\title{
Membrane chemistry
}

Table S1. Elemental analysis (\%) of the unmodified $100 \mathrm{~kg} / \mathrm{mol}$ and modified membranes (before and after soaking in sodium hypochlorite solution).

\begin{tabular}{|c|c|c|c|c|}
\hline Membrane & $\mathrm{C}$ & $\mathrm{H}$ & $\mathrm{N}$ & $\mathrm{S}$ \\
\hline Base membrane (unmodified 100 kg/mol) & 59.2 & 3.7 & n.d. ${ }^{\text {a }}$ & 13.0 \\
\hline PES-g-PEGMA (DG $\left.{ }^{b} \sim 320\right)$ & 59.8 & 4.6 & n.d. ${ }^{a}$ & 12.5 \\
\hline $\begin{array}{l}\text { PES-g-PEGMA (DG 320) after soaking in } \\
\mathrm{NaHClO}_{3}{ }^{\mathrm{C}} \text { for } 2 \text { days }\end{array}$ & 59.7 & 4.8 & n.d. ${ }^{a}$ & 12.4 \\
\hline $\begin{array}{l}\text { PES-g-PEGMA (DG 320) after soaking in } \\
\mathrm{NaHClO}_{3}{ }^{\mathrm{C}} \text { for } 8 \text { days }\end{array}$ & 59.6 & 4.7 & n.d. ${ }^{a}$ & 12.6 \\
\hline PES-g-SPE (DG 165) & 59.5 & 4.6 & n.d. ${ }^{a}$ & 13.3 \\
\hline $\begin{array}{l}\text { PES-g-SPE (DG 165) after soaking in } \\
\mathrm{NaHClO}_{3}{ }^{\mathrm{c}} \text { for } 2 \text { days }\end{array}$ & 59.6 & 4.7 & n.d. ${ }^{\text {a }}$ & 13.3 \\
\hline $\begin{array}{l}\text { PES-g-SPE (DG 165) after soaking in } \\
\mathrm{NaHClO}_{3}{ }^{\mathrm{c}} \text { for } 8 \text { days }\end{array}$ & 59.5 & 4.6 & n.d. ${ }^{a}$ & 13.2 \\
\hline PES-g-PEGMA/MBAA (40/0.4 $\left.{ }^{\mathrm{d}}, \mathrm{DG} \sim 250\right)$ & 59.9 & 4.5 & n.d. ${ }^{a}$ & 12.4 \\
\hline $\begin{array}{l}\text { PES-g-PEGMA/MBAA }\left(40 / 0.4^{\mathrm{d}}, \mathrm{DG} \sim 250\right) \\
\text { after soaking in } \mathrm{NaHClO}_{3}{ }^{\mathrm{c}} \text { for } 2 \text { days }\end{array}$ & 59.7 & 4.7 & n.d. ${ }^{\text {a }}$ & 12.4 \\
\hline $\begin{array}{l}\text { PES-g-PEGMA/MBAA }\left(40 / 0.4^{\mathrm{d}}, \mathrm{DG} \sim 250\right) \\
\text { after soaking in } \mathrm{NaHClO}_{3}{ }^{\mathrm{c}} \text { for } 8 \text { days }\end{array}$ & 59.6 & 4.7 & n.d. ${ }^{a}$ & 12.4 \\
\hline PES-g-PEGMA/MBAA (40/2 ${ }^{\mathrm{d}}$, DG 255) & 59.8 & 4.4 & n.d. ${ }^{a}$ & 12.5 \\
\hline $\begin{array}{l}\text { PES-g-PEGMA/MBAA }\left(40 / 2^{\mathrm{d}} \text {, DG 255) }\right. \\
\text { after soaking in } \mathrm{NaHClO}_{3}{ }^{\mathrm{c}} \text { for } 2 \text { days }\end{array}$ & 59.6 & 4.6 & n.d. $^{\text {a }}$ & 12.4 \\
\hline $\begin{array}{l}\text { PES-g-PEGMA/MBAA }\left(40 / 2^{\mathrm{d}}, \text { DG 255) }\right. \\
\text { after soaking in } \mathrm{NaHClO}_{3}{ }^{\mathrm{c}} \text { for } 8 \text { days }\end{array}$ & 59.7 & 4.6 & n.d. ${ }^{\text {a }}$ & 12.5 \\
\hline PES-g-SPE/MBAA (40/2 ${ }^{\mathrm{d}}$, DG 173) & 59.4 & 4.5 & n.d. ${ }^{a}$ & 13.2 \\
\hline $\begin{array}{l}\text { PES-g-SPE/MBAA (40/2 }{ }^{\mathrm{d}} \text {, DG 173) after } \\
\text { soaking in } \mathrm{NaHClO}_{3}{ }^{\mathrm{C}} \text { for } 2 \text { days }\end{array}$ & 59.5 & 4.6 & n.d. ${ }^{a}$ & 13.2 \\
\hline $\begin{array}{l}\text { PES-g-SPE/MBAA }\left(40 / 2^{\mathrm{d}} \text {, DG 173) after }\right. \\
\text { soaking in } \mathrm{NaHClO}_{3}{ }^{\mathrm{c}} \text { for } 8 \text { days }\end{array}$ & 59.5 & 4.6 & n.d. ${ }^{a}$ & 13.2 \\
\hline
\end{tabular}

${ }^{a}$ n.d. not detected 
${ }^{\mathrm{b}}$ degree of grafting $\left(\mu \mathrm{g} / \mathrm{cm}^{2}\right)$

c $500 \mathrm{mg} / \mathrm{L}$ active chlorine

${ }^{d}$ monomer/cross-linker concentration used for modification $((g / L) /(g / L))$

\section{Contact Angle}

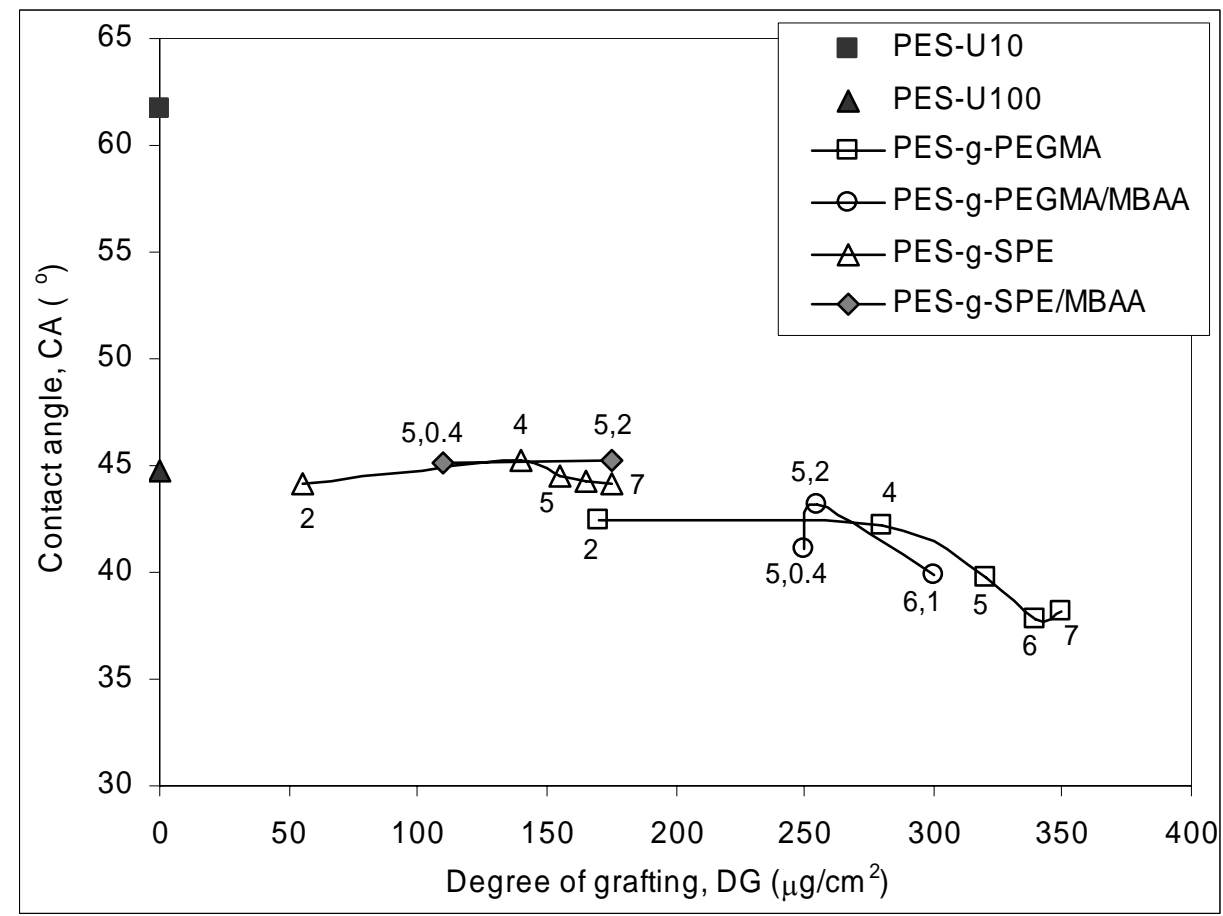

Figure S1. Captive bubble contact angles of unmodified and modified membranes with and without cross-linker (monomer concentration of $40 \mathrm{~g} / \mathrm{L}$ ) at various DGs. The number inside the picture indicates the UV irradiation time (for single) and UV irradiation time and cross-linker concentration (g/L), respectively (for couple). 


\section{Surface morphology}

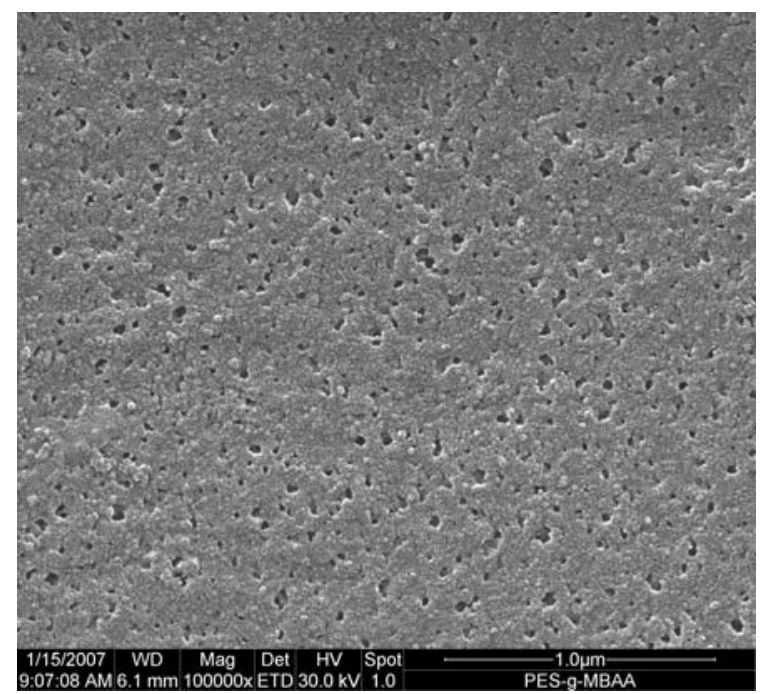

Figure S2. SEM micrograph of a membrane photo-grafted from a solution containing only cross-linker monomer (MBAA) with 8 min UV irradiation.

\section{Effect of modification on membrane hydraulic permeability and membrane-solute interaction}

(adsorptive fouling). These data are presented to support the interpretation of membrane rejection and membrane performance analysis. The results are expressed in terms of permeability ratio (cf. Eq. (3), Article) and relative flux reduction (cf. Eq. (4), Article).

For the modification without cross-linker (Figures S3 and S4), as the DG was increased, both hydraulic permeability ratio and relative flux reduction would decrease indicating that modified membranes had lower flux, but also had less solute adsorption. In addition, it was found that for similar DG, modification using PEGMA yielded membranes with higher permeability as well as RFR than modification using SPE. The latter indicates that PEGMA-modified membrane had higher adsorption with protein whereas it has previously shown that PEGMA was more swollen than SPE (see Article, zeta potential). This result might be due to the difference in surface coverage as well as grafted chain structure leading to different pore structure (cf. rejection analysis, Article). Then, it will be more 
reasonable to compare also membranes having similar rejection curves in order to minimize the effect of pore structure (cf. Membrane performance based on permeability-adsorptive fouling resistance analysis, Article). Modification with the same monomer concentration and UV irradiation yielded membranes having higher permeability and lower RFR for PEGMA than for SPE. There was no modified membrane which is absolutely inert toward protein adsorption. This observation supports the contribution of pore structure on the solid surface-solute interaction during adsorption on the membrane surface.

Overall, the presence of cross-linker caused decreasing in the membrane permeability more significant than in the absence of cross-linker (Figures S5 and S6). The 3D grafted chain structure formed by cross-linking diminished the inter-chain volume and then reduced the hydraulic permeability. The RFR achieved by cross-linked modified membranes was slightly higher for PEGMA but significantly higher for SPE than uncross-linked. However, for both monomers, it was observed that the presence of cross-linker could lead to increase and decrease of the RFR. Briefly, the increase in RFR by cross-linking might be due to heterogeneity of the surface layer (see Article in more detail). Consequently, the nature of the cross-linker itself might also contribute to the increasing in RFR. 


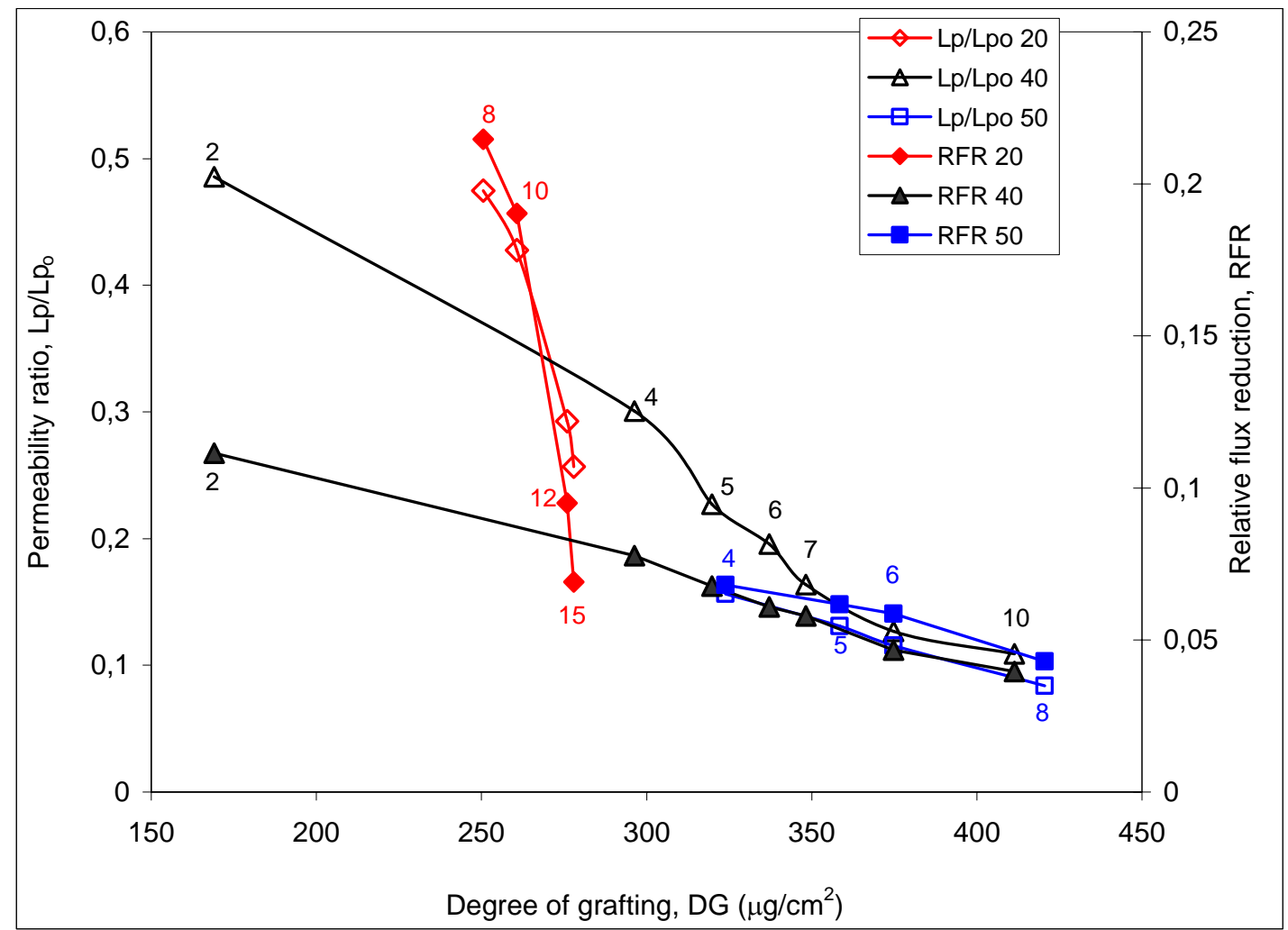

Figure S3. Effect of modification using PEGMA on the membrane hydraulic permeability and adsorptive fouling using myoglobin ( $1 \mathrm{~g} / \mathrm{L}, \mathrm{pH}$ 7, 2 h exposure). The number inside the picture indicates the UV irradiation time whereas in the legend the monomer concentration is given (in $\mathrm{g} / \mathrm{L}$ ). 


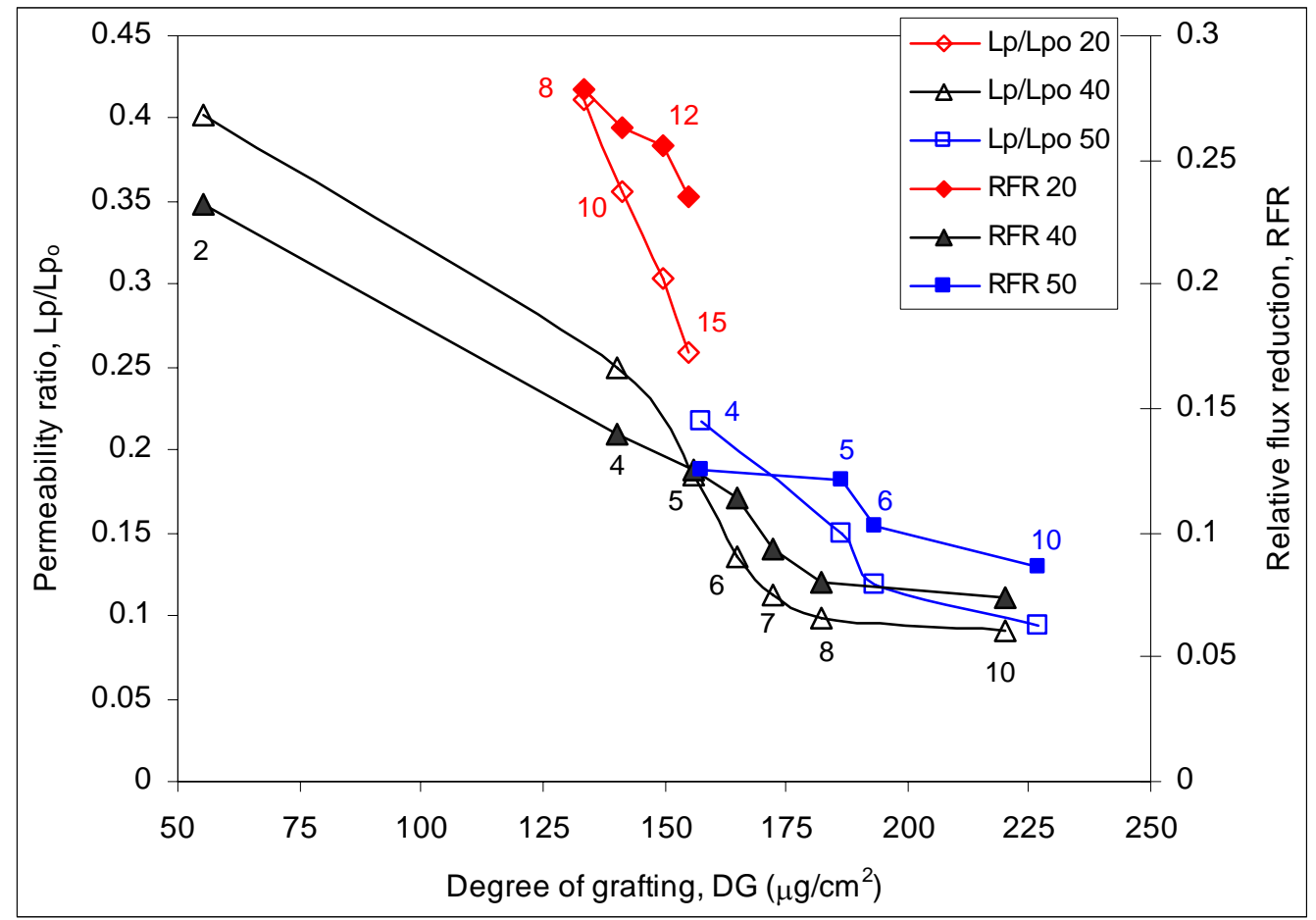

Figure S4. Effect of modification using SPE on the membrane hydraulic permeability and adsorptive fouling using myoglobin ( $1 \mathrm{~g} / \mathrm{L}, \mathrm{pH}$ 7, 2 h exposure). The numbers inside the picture indicate the UV irradiation time whereas in the legend the monomer concentration is given (in $\mathrm{g} / \mathrm{L}$ ). 


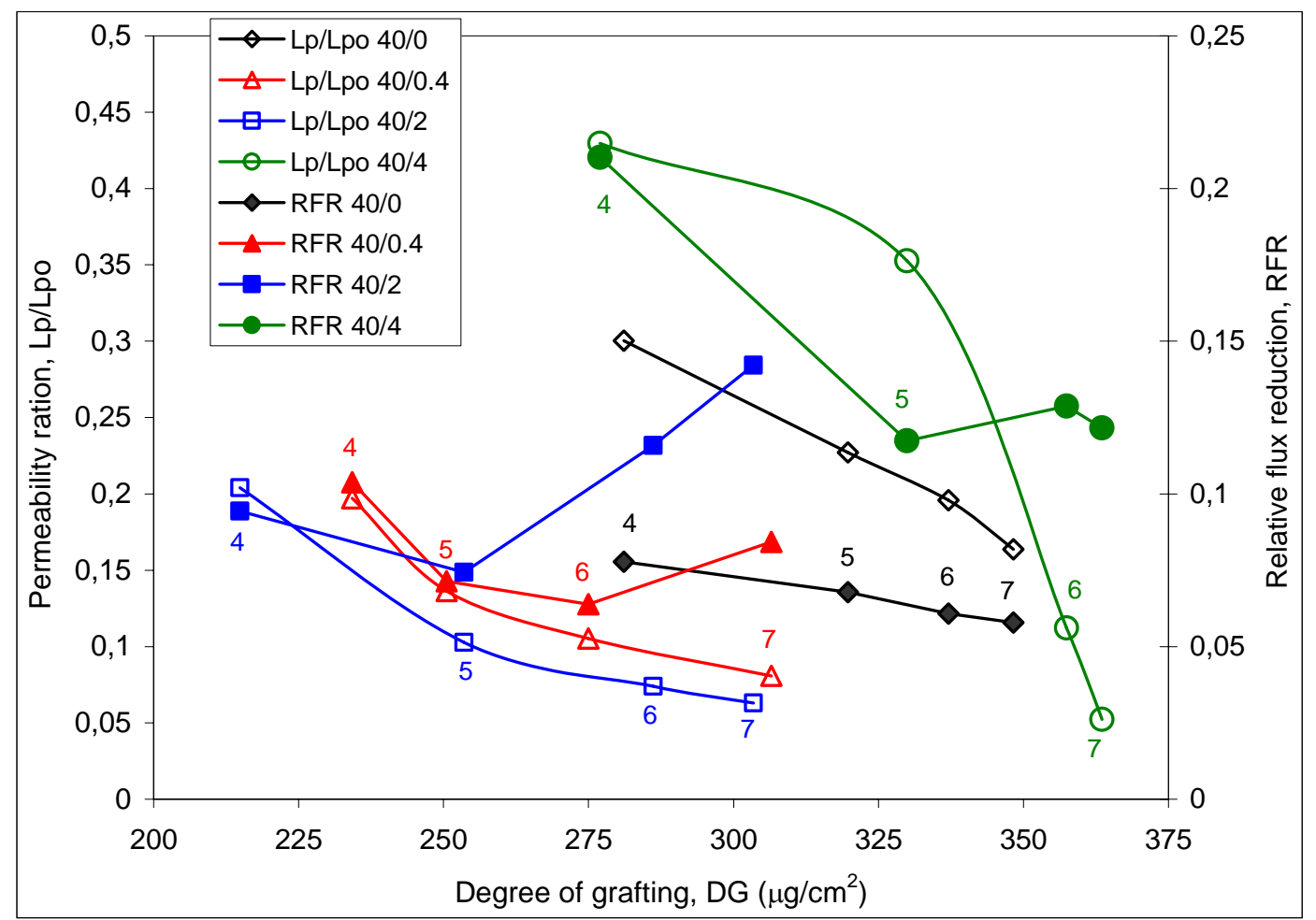

Figure S5. Effect of modification using PEGMA and cross-linker on membrane hydraulic permeability and adsorptive fouling using myoglobin (1 g/L, $\mathrm{pH}$ 7, 2 h exposure). The numbers inside the picture indicate the UV irradiation time whereas in the legend the monomer and cross-linker concentrations are given (in g/L). 


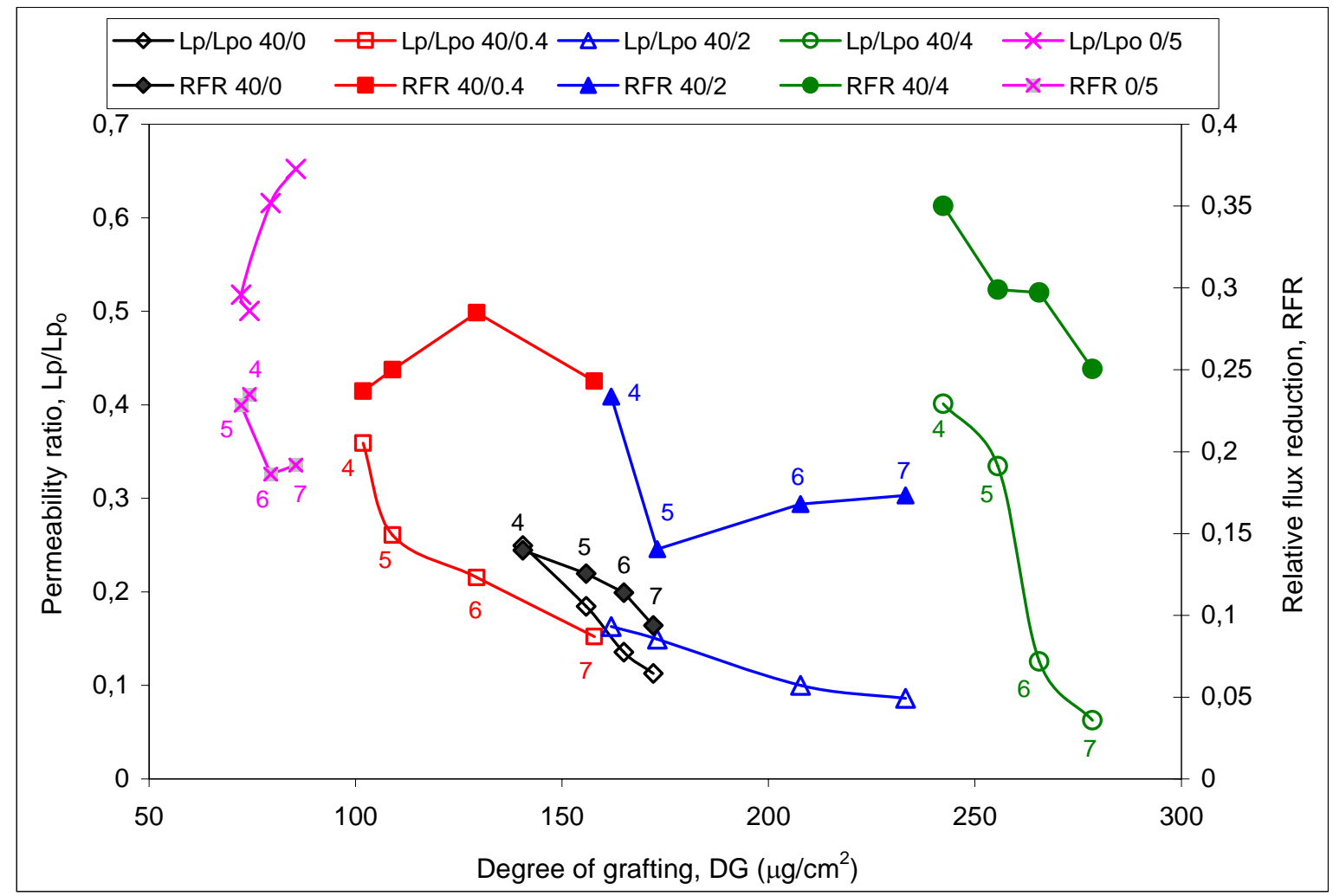

Figure S6. Effect of modification using SPE and cross-linker on membrane hydraulic permeability and adsorptive fouling using myoglobin ( $1 \mathrm{~g} / \mathrm{L}, \mathrm{pH}$ 7, 2 h exposure). The numbers inside the picture indicate the UV irradiation time whereas in the legend the monomer and cross-linker concentrations are given (in g/L). Note, that “Lp/Lpo 0/5” and “RFR 0/5” are data for PES membranes photo-grafted from solutions containing cross-linker monomer (MBAA) only. 